\title{
Analysis of the Relationship between Changes in Meteorological Conditions and the Variation in Summer Ozone Levels over the Central Kanto Area
}

\author{
Mai Khiem, ${ }^{1}$ Ryozo Ooka, ${ }^{2}$ Hong Huang, ${ }^{3}$ Hiroshi Hayami, ${ }^{4}$ Hiroshi Yoshikado, ${ }^{5}$ \\ and Yoichi Kawamoto ${ }^{2}$ \\ ${ }^{1}$ Graduate School of Engineering, The University of Tokyo, 4-6-1 Komaba, Meguro-ku, Tokyo 153-8505, Japan \\ ${ }^{2}$ Institute of Industrial Science, The University of Tokyo, 4-6-1 Komaba, Meguro-ku, Tokyo 153-8505, Japan \\ ${ }^{3}$ Center for Public Safety Research, Department of Engineering Physics, Tsinghua University, Beijing 100084, China \\ ${ }^{4}$ Central Research Institute of Electric Power Industry, 1646 Abiko, Abiko-shi, Chiba 270-1194, Japan \\ ${ }^{5}$ Graduate School of Science and Engineering, Saitama University, 255 Shimo-okubo Sakura-Ku, Saitama 338-8570, Japan
}

Correspondence should be addressed to Mai Khiem, khiem@iis.u-tokyo.ac.jp

Received 9 November 2009; Revised 15 March 2010; Accepted 13 May 2010

Academic Editor: Raymond Desjardins

Copyright ( 2010 Mai Khiem et al. This is an open access article distributed under the Creative Commons Attribution License, which permits unrestricted use, distribution, and reproduction in any medium, provided the original work is properly cited.

\begin{abstract}
An increasing trend in ground-level ozone $\left(\mathrm{O}_{3}\right)$ concentrations has recently been recognized in Japan, although concentrations of ozone precursors, nitrogen oxides (NOx), volatile organic compounds (VOCs) and nonmethane hydrocarbons (NMHCs) have decreased. In this paper, the relationship between meteorological factors (temperature and wind speed) and ground-level ozone concentrations in the summer over the central Kanto area of Japan was examined using both statistical analyses and numerical models. The Fifth-Generation NCAR/Penn State Mesoscale Model (MM5) and the Community Multiscale Air Quality (CMAQ) model were employed in this study. It was found that there is a close relationship between meteorological conditions and ground-level ozone concentrations over the central Kanto area. In summer, up to $84 \%$ of the long-term variation in peak ozone concentrations may be accounted for by changes in the seasonally averaged daily maximum temperature and seasonally averaged wind speed, while about $70 \%$ of the recent short-term variation in peak ozone depends on the daily maximum temperature and the daily averaged wind speed. The results of numerical simulations also indicate that urban heat island (UHI) phenomena can play an important role in the formation of high ozone concentrations in this area.
\end{abstract}

\section{Introduction}

A high concentration of ground level ozone has been recognized as a harmful pollutant for decades because it is the primary ingredient in photochemical smog and has detrimental effects on human health and the environment [1]. In the Kanto region, the most highly developed, urbanized, and industrialized part of Japan (see Figure 1), high ozone episodes frequently occur during the summer season. According to the Tokyo Metropolitan Government Environmental White Paper from 2006 (http://www.kankyo.metro.tokyo.jp/), the concentrations of most air pollutants are decreasing in the Tokyo Metropolitan area due to the application of exhaust control regulations to factories and industrial complexes and the introduction of regulations to control diesel emissions from automobiles. However, the concentration of photochemical oxidants has not been lowered to the Environmental Quality Standards in Japan (a one-hour value (i.e., averaged over one hour) of 60 parts per billion (ppb) or less), and the number of days on which high concentrations of ozone (one-hour ozone concentrations in excess of $120 \mathrm{ppb}$ ) are recorded has been increasing. Figure 2 shows the annually averaged values of ozone, NOx, and NMHCs from 1990 to 2005 in the Tokyo area. It is evident that both NOx and NMHCs show a decreasing tendency, while ozone concentrations show an increasing tendency for the last two decades. Possible reasons for this ozone trend determined by using both models and measurements [2-6] have been discussed. Most of these studies have indicated that long-range transported 


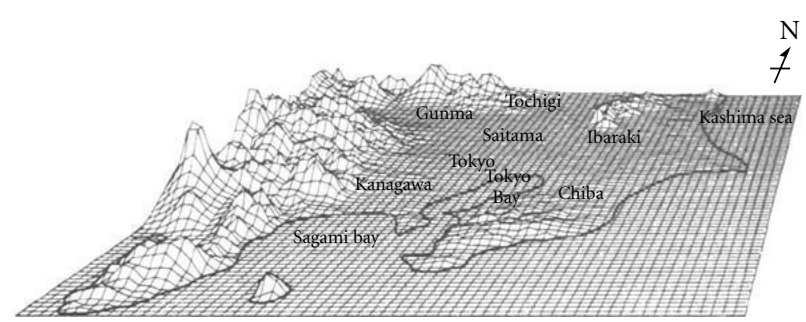

Figure 1: Topography of the Kanto area viewed from the south-east direction (source: Uno et al. [7]).

ozone and its precursors from East Asia, particularly China, have been rapidly increasing during the past two decades and are the main cause of the recent increase in ozone concentrations over Japan. The contributions from changes in transboundary air pollution are the largest during spring $[2,3]$. However, it is a fact that the concentrations of ozone, especially alarming ozone levels (one-hour ozone concentrations in excess of $120 \mathrm{ppb}$ ), around major cities have also been rising in summer, although clean air flows predominate due to southerly winds from the Pacific Ocean during this season. High summer ozone levels suggest that, besides the transboundary pollution, another reason for the cause of the increase in peak ozone concentrations in summer should be considered.

It is well known that meteorology plays an important role in the formation, transport, and dispersion of air pollutants. As a result, changes in local meteorological conditions, such as the wind direction, wind speed, relative humidity, and temperature, can greatly affect variations in ozone concentrations [8-13]. Therefore, analyses of the influences of the changes in meteorological conditions on variations in ozone are very helpful for better understanding variations in ozone concentrations. In recent years, meteorological effects on variations in surface ozone concentrations have been extensively studied $[10,12,14-21]$. These studies have shown that meteorological conditions can have significant impacts upon surface ozone concentrations. For instance, Zhang et al. [10] found that summertime ozone concentrations increase during periods of high temperatures in the northeastern United States. Tarasova and Karpetchko [18] investigated the relationship between local meteorological conditions and the variability in surface ozone at Lovozero (Kola Peninsula) for the period of 1999-2000 and found that 70\% of the dayto-day ozone variability could be explained by changes in temperature, relative humidity, and wind speed. Cheng et al. [20] analyzed the effect of meteorological factors on the trend of surface ozone during the period of 2000-2003 in Taiwan. They suggested that the meteorological conditions in southern Taiwan tend to increase ozone concentrations during this period. Kovač-Andrić et al. [21] analyzed the impact of meteorological factors on ozone levels in Slavonia (Croatia) and indicated that $67 \%$ of the variation of in ozone concentrations during the summer of 2002 could be accounted for by changes in temperature, solar radiation, and wind speed.

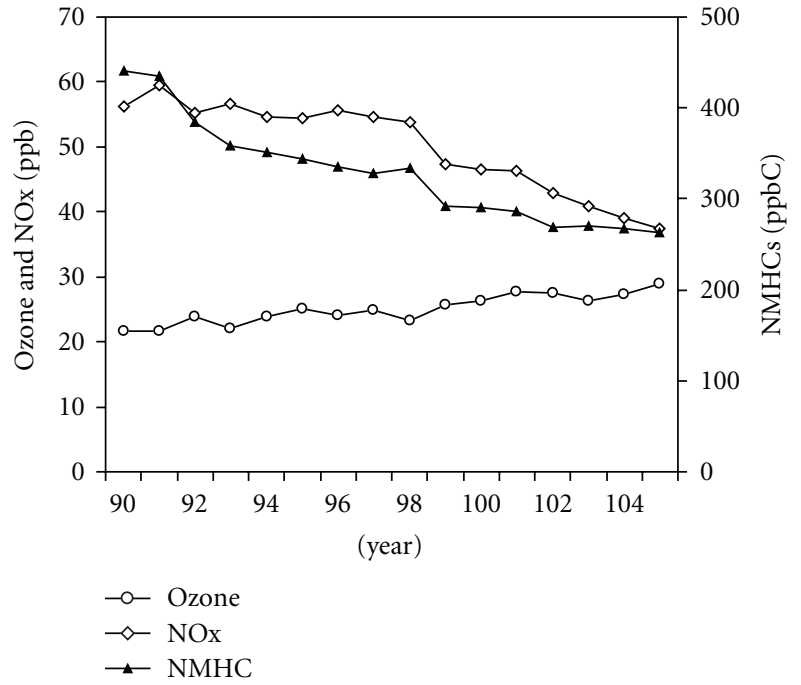

FIGURE 2: Annual average pollutant concentrations during 19902005 in the Tokyo area (see Figure 8; source: National Institute for Environmental Studies, Japan).

In Japan, relationships between meteorological conditions and air pollution in general and photochemical ozone in particular over the Kanto area have been extensively studied [7, 22-30]. Most previous researchers have used observational data to analyze the role of local meteorological conditions, such as the land/sea breeze, mountain/valley circulations, and the heat island effect in the Tokyo Metropoli$\tan$ area, in the formation and transport of air pollution. Of the studies listed above, Yoshikado and Tsubaki [22] showed that the recent increase in ozone levels is related to the increased frequency of high-pressure systems over the Kanto area.

Along with global warming, urban warming due to rapid urbanization has an effect on local meteorological conditions; for example, research by Fujibe [31,32] showed that trends for a long-term reduction in wind speed and an increase in temperature occur across many cities in Japan. It has been well documented that high temperatures can directly enhance ozone concentrations by affecting ozone photochemistry as well as ozone precursor emission rates, while wind speed is an important factor in the dispersion of air pollutants. On the other hand, high temperature and low wind speed are usually (but not always) associated with stagnant meteorological conditions that are conducive to accelerated tropospheric ozone formation and accumulation. Figure 3 shows the time series of daily maximum ozone concentrations in the Tokyo area and daily maximum temperatures from 1985-2005 at the Nerima site, Tokyo. This site exhibits a typical pattern for an urban climate. The increases in temperatures and ozone concentrations during the past 21 years are clearly seen in this figure, and a high correlation between the long-term variation in peak ozone concentrations and daily maximum temperatures is apparent. High temperatures and low wind speeds are promoted by the urban heat island effect. Thus, urban heat islands are expected to affect ozone formation. 


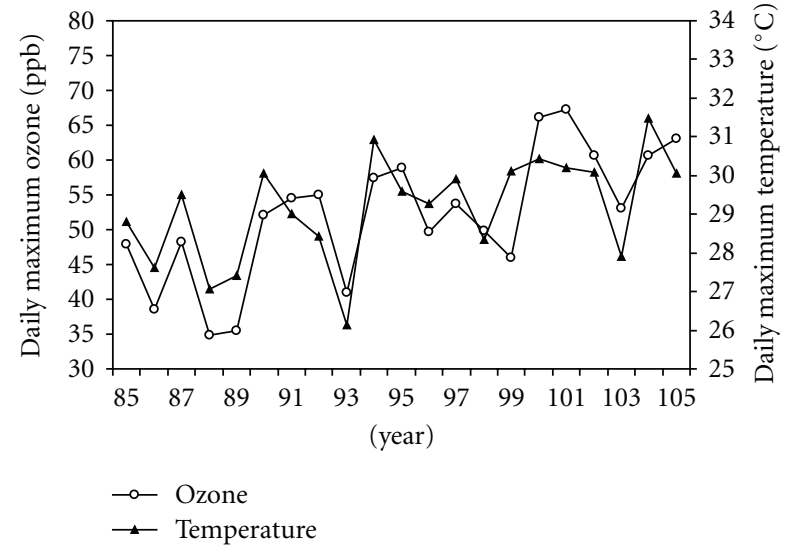

FIGURE 3: Long-term changes in daily maximum ozone concentrations in the Tokyo area and daily maximum temperatures at Nerima in the summer (source: National Institute for Environmental Studies and the Japan Meteorology Agency-JMA, Japan). The summer season is defined here as the average value of the summer months, that is, June, July, and August (according to the definition of the JMA).

In this paper, the authors have investigated the relationship between meteorological conditions (temperature and wind speed) and ozone levels in summer over the central Kanto area. We first estimated the relationship between the variations in ozone levels and changes in meteorological conditions by using both measurements and numerical simulations with the MM5/CMAQ model. Then we examined the effects of urban heat islands on ozone concentrations based on the simulation results. The results of this study are intended to add to the body of knowledge concerning the effect of meteorological conditions on variations in summer ozone levels over the central Kanto area.

\section{Statistical Methods and Measurements}

2.1. Regression Analysis. To assess how meteorological conditions affect variations in ozone levels, the authors used multiple linear regression analysis. This is one of the most widely used methods for predicting how ozone concentrations depend on meteorological factors. The general equation for the model was as follows:

$$
y=a_{0}+a_{1} x_{1}+\cdots+a_{m} x_{m}+\varepsilon,
$$

where $y$ is an objective variable (ozone concentrations); $m$ is the number of independent variables (meteorological variables); $x_{j}$ are independent variables; $a_{j}$ are regression coefficients (estimated using the least squares procedure); $\varepsilon$ is an error term associated with the regression analysis.

2.2. Measured Data. An overview of all of the variables used in the regression analysis is shown in Table 1. The past 21 years (1985 to 2005) of data for the seasonally averaged daily maximum ozone concentrations during the summer (the predicted variable in the model) at 34 environmental monitoring sites in the Tokyo area were used to analyze the long-term variation in ozone levels. These data were obtained from the National Institute for Environmental Studies (NIES), Japan. Actually, in Japan, the ozone data are monitored as photochemical oxidants, most of which are composed of ozone, and the measurement quality is administered by the Ministry of Environment. For independent variables (predictors), determining which and how many meteorological variables need to be included in a model is a somewhat subjective and difficult task because they are not really independent. For example, high temperature may be associated with high solar radiation and low humidity. Therefore, to minimize such confusion, the authors selected only two parameters to estimate the effect of local meteorological conditions. These were the seasonally averaged daily maximum temperature and the seasonally averaged wind speed for the summer measured at the Nerima meteorological site (Tokyo, $35^{\circ} 44.1^{\prime} \mathrm{N}$ and $139^{\circ} 40.1^{\prime} \mathrm{E}, 38 \mathrm{~m}$ above sea level) during the period from 1985-2005. These data were obtained from the JMA of Japan. Additionally, the measurements of ozone, temperature, and wind speed from monitoring sites throughout the Tokyo area during a typical summer month (August 2005) were also used to analyze the recent short-term variation in ozone levels. These data were obtained from the NIES.

\section{Numerical Model Description}

3.1. Meteorology Modeling. The MM5 model version 3.7, a limited-area, nonhydrostatic, terrain-following sigmacoordinate model [33], was used in this research to provide spatial and temporal distributions of meteorological fields to the air quality model. It has characteristics such as (i) a multiple-nest capability, (ii) nonhydrostatic dynamics, which allows the model to be used at a scale of several kilometers, (iii) multitasking capabilities on sharedand distributed-memory machines, (iv) a four-dimensional data-assimilation capability (FDDA), and (v) more physics options.

3.2. Air Quality Modeling. The CMAQ model version 4.6 developed by the Environmental Protection Agency (USA), which was released in 2006, was used in this study. It is a multiscale and multiple pollutant chemistry-transport model that includes all the critical scientific processes such as atmospheric transport, deposition, cloud mixing, emissions, gas- and aqueous-phase chemical transformation processes, and aerosol dynamics and chemistry. The CMAQ system can simulate concentrations of tropospheric ozone, acid deposition, visibility, fine particulates, and other air pollutants in the context of a "one atmosphere" approach, involving complex atmospheric pollutant interactions on regional and urban scales.

3.3. Meteorology-Chemistry Interface Processor. The input meteorological data for the CMAQ model were generated by the MM5 model. The one-way coupling of MM5 to CMAQ is accomplished through a meteorology-chemistry interface processor (MCIP) that handles window domains 
TABLE 1: Variables used in the regression analysis.

\begin{tabular}{ll}
\hline Variables & Definition \\
\hline & (i) Seasonally averaged daily maximum value of environmental monitoring sites in the Tokyo area (see \\
Ozone $\left(\mathrm{O}_{3}\right)$ & Figure 8 ) for the summers from 1985-2005. $\mathrm{O}_{3}$ concentrations are expressed in ppb.
\end{tabular}

(ii) Averaged daily maximum value of environmental monitoring sites in the Tokyo area in August 2005.

(i) Seasonally averaged daily maximum values at the Nerima meteorological site for the summers from Temperature (T) 1985-2005. Temperatures are expressed in ${ }^{\circ} \mathrm{C}$.

(ii) Averaged daily maximum values of environmental monitoring sites in the Tokyo area in August 2005.

(i) Seasonally averaged values at the Nerima meteorological site for the summers from 1985-2005. Wind speeds are expressed in $\mathrm{m} \cdot \mathrm{s}^{-1}$.

(ii) Daily averaged values of environmental monitoring sites in the Tokyo area in August 2005.

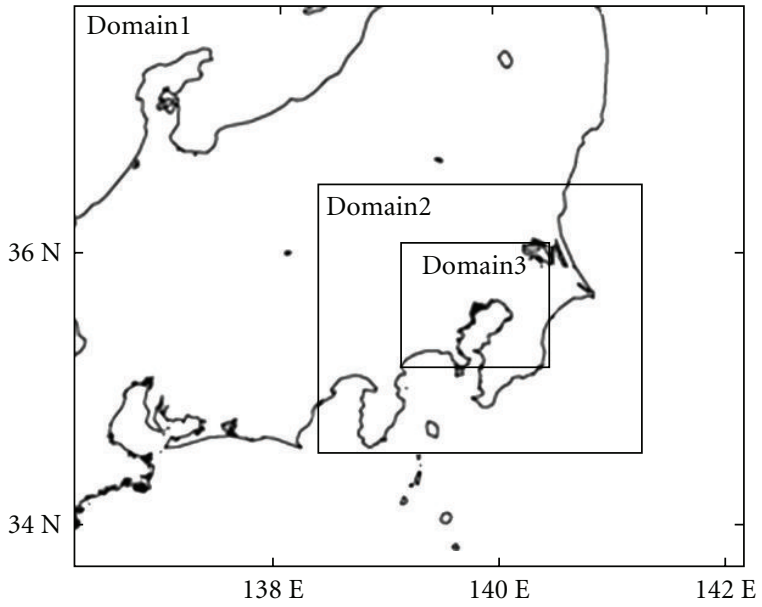

Figure 4: Analysis domains for the MM5/CMAQ simulation.

mapping, data format translation, units conversion, diagnostic estimations of derived variables, and reconstruction of meteorological input on different horizontal and vertical grids through simple bilinear interpolation [34].

3.4. Outline and Setting of the Numerical Experiments. In this study, the MM5 simulation was performed with three nested domains (Figure 4). A detailed configuration of the model is summarized in Table 2. The three domains cover a region of Kanto with grid resolutions of $9 \mathrm{~km}, 3 \mathrm{~km}$, and $1 \mathrm{~km}$, respectively. All of the domains have 23 vertical sigma levels from the surface to the $100-\mathrm{hPa}$ level, with a denser distribution near the surface and looser one near the top. There are eight total layers prescribed in the planetary boundary layer. The $\sigma$ coordinate of the lowest layer is at 0.998 , which is equivalent to up to about 14 meters above ground.

The physics options of the model configuration in the MM5 simulation were as follows: Grell cumulus parameterization scheme [35], MRF planetary boundary layer scheme [36], explicit simple ice microphysics [37], cloud-radiation scheme [38], and FDDA. The cumulus parameterization scheme was not used for the 3 and $1 \mathrm{~km}$ domains. The
TABLE 2: Analysis domain sizes and grid resolutions.

\begin{tabular}{cccc}
\hline Domains & $\begin{array}{c}\text { Computation } \\
\text { domain } \\
(X[\mathrm{~km}] \times Y[\mathrm{~km}])\end{array}$ & $\begin{array}{c}\text { Grid number } \\
\left(n x_{x} n y_{x} n z\right)\end{array}$ & $\begin{array}{c}\text { Horizontal } \\
\text { resolution }(\mathrm{km})\end{array}$ \\
\hline Domain 1 & $450 \times 540$ & $51 \times 61 \times 23$ & 9 \\
Domain 2 & $216 \times 261$ & $73 \times 88 \times 23$ & 3 \\
Domain 3 & $99 \times 120$ & $100 \times 121 \times 23$ & 1 \\
\hline
\end{tabular}

CMAQ was configured with the following options: (1) CBIV speciation with aerosol and aqueous chemistry, (2) the Piecewise Parabolic Method for both horizontal and vertical advection, (3) eddy vertical diffusion, (4) photolysis, (5) no Plume-in-Grid, (6) the EBI chemistry solver configured for CB-IV, (7) the use of the third-generation aerosol model, (8) the use of the second-generation aerosol deposition model, and (9) the use of the RADM cloud model. A more detailed description of the scientific mechanisms and implementations of CMAQ can be found in Byun and Ching [34]. To shorten the computation time and reduce the size of output files, the 23-layer output of the MM5 model was transformed into 14 layers that were used as inputs for the CMAQ model through MCIP program. These layers were also denser near the surface, and the lowest layer was up to about 14 meters above the ground.

One typical summer month (August, 2005) during which one-hour observed ozone concentrations peaked at over $120 \mathrm{ppb}$ at many sites in the Kanto area was selected for the MM5/CMAQ simulation. Final analysis data (FNL) from the National Centers for Environmental Prediction (NCEP) with a horizontal resolution of $1^{\circ} \times 1^{\circ}$ and a temporal resolution of six hours were used to provide the initial and boundary conditions for the MM5 model and the FDDA process. The terrain, land use, and land-water mask datasets were obtained from the United States Geological Survey (USGS) global covers. The USGS 25-category land use/land cover classification system was used to determine the single dominant land use category for each computational cell. The hourly NMHC and NOx emissions data used in this study were provided by [39]. For example, the data at 14:00 JST for the $3 \times 3 \mathrm{~km}$ grid were shown in Figure 5. These data included emissions from biogenic sources, area sources, point sources and mobile sources. 

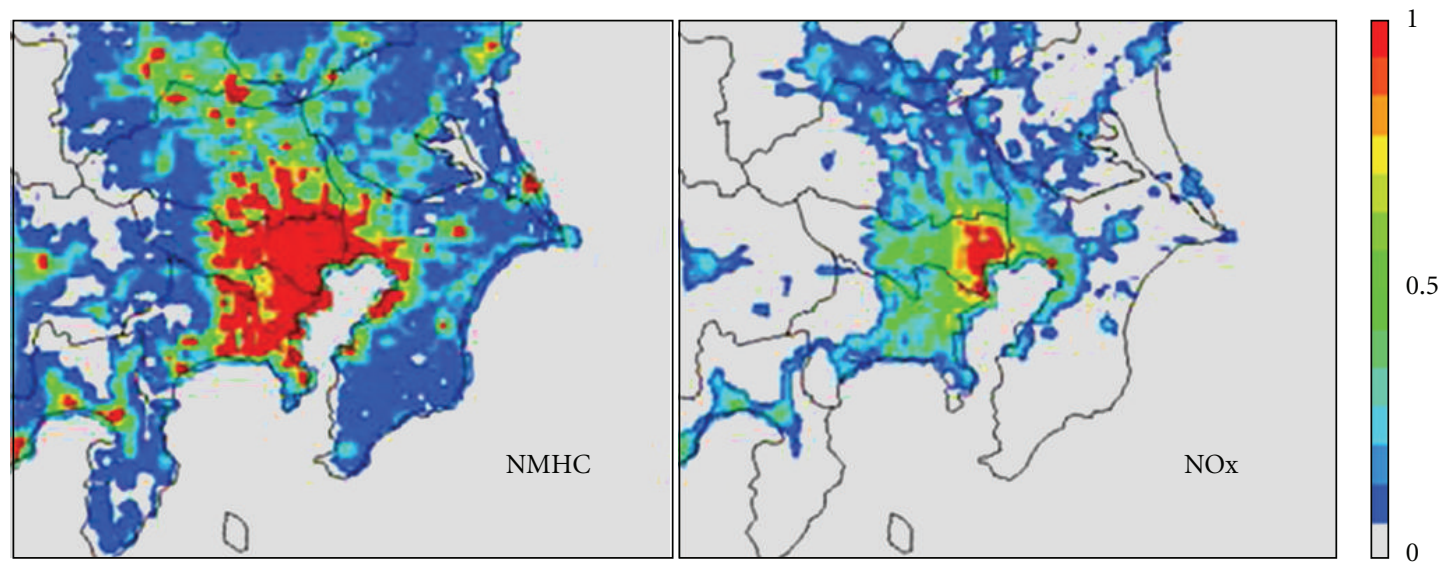

FIgURE 5: Hourly emissions data for the CMAQ model at 14:00 JST (mole/s/grid).

TABLE 3: Initial and boundary conditions of some pollutants (in ppb) for the CMAQ model.

\begin{tabular}{|c|c|c|c|c|c|c|c|c|c|c|c|c|}
\hline \multirow{2}{*}{\multicolumn{2}{|c|}{$\begin{array}{c}\text { Species } \\
\text { ICs }\end{array}$}} & $\mathrm{O}_{3}$ & $\mathrm{NO}$ & $\mathrm{NO}_{2}$ & ALD & FORM & ETH & OLE & TOL & XYL & ISO & PAR \\
\hline & & 28 & 2.0 & 4.0 & 1.8 & 2.2 & 1.4 & 1.6 & 14.4 & 0.6 & 0.5 & 74.3 \\
\hline \multirow{4}{*}{ BCs } & $\mathrm{N}$ & 28 & 2.0 & 4.0 & 1.8 & 2.2 & 1.4 & 1.6 & 14.4 & 0.6 & 0.5 & 74.3 \\
\hline & $\mathrm{E}$ & 25 & 2.0 & 4.0 & 1.8 & 2.2 & 1.4 & 1.6 & 14.4 & 0.6 & 0.5 & 74.3 \\
\hline & $\mathrm{W}$ & 30 & 2.0 & 4.0 & 2.0 & 2.4 & 3.2 & 4.2 & 11.4 & 0.7 & 0.5 & 82.7 \\
\hline & $S$ & \multicolumn{11}{|c|}{ CMAQ Default } \\
\hline
\end{tabular}

$\mathrm{O}_{3}$ : ozone; NO: nitric oxide; $\mathrm{NO}_{2}$ : nitrogen dioxide; PAR: paraffin carbon bond; ETH: ethylene; OLE: olefin; TOL: toluene; XYL: xylene; FORM: formaldehyde; ALD: aldehydes; ISO: isoprene.

The MM5 simulation was performed from 09:00 JST July 31 to 00:00 JST August 31, 2005. The first 15 hours of the MM5 simulation constituted a "spin up" period for cloud processes and was not used for the CMAQ simulation. After the MM5 simulation, the CMAQ model was performed for Domain 2 with the initial and boundary conditions derived from a climatological profile of atmospheric pollutants (clean air; as described in Byun and Ching [34]) and the observational report of the Japan Clean Air Program [40] (as shown in Table 3). During summer, the Kanto area was mainly dominated by clean air masses due to southerly winds from the Pacific Ocean. Therefore, a clean air condition was selected for the south boundary to minimize the effect of boundary conditions. Finally, output from the CMAQ model for Domain 2 was used to produce the initial and boundary conditions for its simulation of Domain 3. The results of the CMAQ and MM5 simulations for Domain 3 were used to analyze the relationship between meteorological conditions and ozone concentrations.

\section{Results and Discussion}

4.1. Relationship between Long-Term Variations in Measured Ozone Levels and Meteorological Conditions in Summer. Using a multiple linear regression method, prediction equations for ozone concentrations were developed based on the meteorological parameters mentioned above. The seasonally averaged daily maximum ozone concentration was the dependent variable in the multiple regression analysis, while seasonally averaged daily maximum temperature and seasonally averaged wind speed were used as independent variables. Before applying the regression analysis procedure, all of the variables were standardized as follows:

$$
a=\frac{a-\bar{a}}{\sigma} .
$$

Here, $a$ refers to either the ozone, temperature, or wind speed, while $\bar{a}$ and $\sigma$ are their average values and standard deviations, respectively.

The multiple regression results for the standardized values of the seasonally averaged daily maximum ozone concentrations in summer are as follows:

$$
\mathrm{O}_{3}=0.80 * \mathrm{~T}-0.49 * \mathrm{U}, \quad R^{2}=0.84,
$$

where $R^{2}$ is the fraction of the variance explained by the regression.

We performed $t$-tests (based on the Student's $t$ distribution) to test the significance of the coefficients in (3). The results show that the regression coefficients for temperature and wind speed are statistically significant. The $P$-values for both coefficients are less than.05 $(P$-value $<.05)$. The peak ozone concentrations predicted by the statistical regression equation were plotted against the observed values, as shown in Figure 6. The results of the high correlation from this analysis indicate that peak ozone concentrations are strongly affected by meteorological conditions. During 


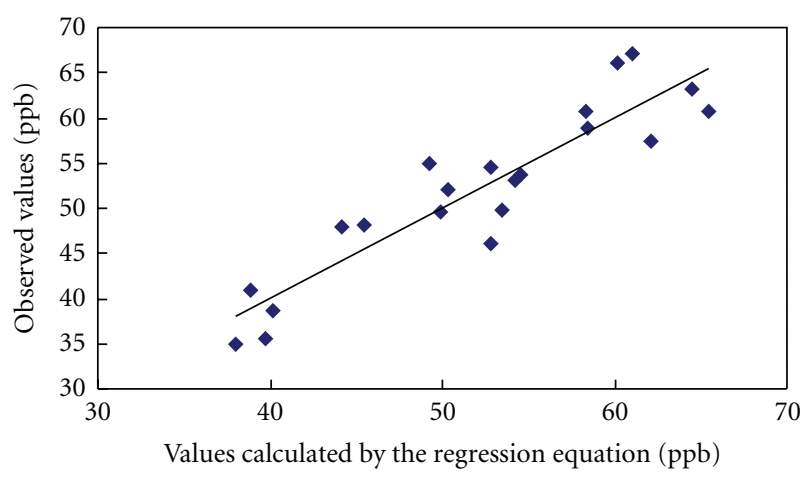

FIgURE 6: The observed seasonally averaged daily maximum $\mathrm{O}_{3}$ concentrations for summer in the Tokyo area plotted against those predicted by the regression equation.

TABLE 4: The observed and predicted (by the statistical regression equation) seasonally averaged daily maximum $\mathrm{O}_{3}$ concentrations in the Tokyo area.

\begin{tabular}{lccc}
\hline & Periods & Observation & $\begin{array}{c}\text { Statistical } \\
\text { regression } \\
\text { equation }\end{array}$ \\
\hline Averaged daily & $1980 \mathrm{~s}$ & 41.0 & 41.5 \\
maximum & $1990 \mathrm{~s}$ & 51.8 & 52.3 \\
concentrations (ppb) & 2000s & 61.8 & 60.6 \\
\hline Difference between & 1990s-1980s & 10.7 & 10.7 \\
periods (ppb) & 2000s-1990s & 10.0 & 8.4 \\
\hline
\end{tabular}

summer, about $84 \%$ of the long-term variation in peak ozone concentrations may be accounted for by changes in temperature and wind speed.

The seasonally averaged daily maximum concentrations and the differences in the peak summer ozone concentrations between periods as estimated by the statistical regression equation approach are shown in Table 4 . Similarly to the observed ozone trends, an increasing trend is found during this period (1985-2005). High increases are detected in the summer, with average peak ozone concentrations of $41.5,52.3$ and $60.6 \mathrm{ppb}$ for the $1980 \mathrm{~s}, 1990 \mathrm{~s}$, and $2000 \mathrm{~s}$, respectively. The $t$-test shows that the differences between these average peak ozone concentrations are statistically significant $(P$-value $<.05)$. This suggests that meteorological conditions may contribute to the increasing trend for peak ozone concentrations in Tokyo. Any remaining variability could be attributed to other causes, such as long-range transported ozone and its precursors from the East Asian continent, production from chemical reactions, and other meteorological variables that were not included in the statistical regression.

4.2. Relationship between Recent Short-Term Variations in Measured Ozone Levels and Meteorological Conditions during a Typical Summer Month. Ozone variation is influenced by changes in meteorological conditions occurring at various time scales: short-term, season-to-season, and long-term.

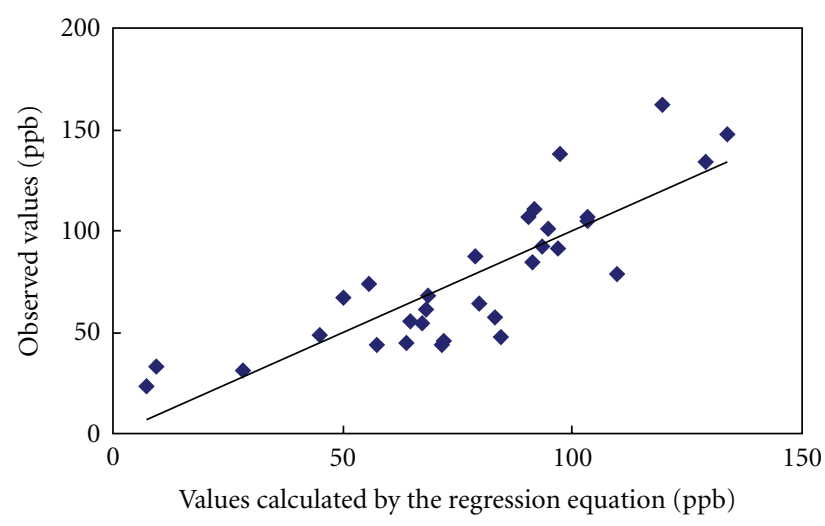

FIgURE 7: The observed daily maximum $\mathrm{O}_{3}$ concentration for August 2005 in the Tokyo area plotted against those predicted by the regression equation.

For this study, we were interested in the variation in daily maximum ozone concentrations caused by shortterm changes in meteorological conditions. Additionally, we would like to validate the accuracy of numerical simulation in comparison with the result of the short-term analysis as well. For this purpose, the daily measurements from one typical summer month (August 2005) were used for a representative analysis. The measurements used were the daily maximum ozone concentrations, maximum temperatures, and average daily wind speeds, which were all measured at the same environmental monitoring sites in the Tokyo area. We note also that the short-term analysis for only one month may be somewhat uncertain; however, we selected this period so as to be in accordance with the model-based analysis, intending to obtain information about the validity of the model simulation. After standardizing all of the variables using (2) and applying the same procedure for regression analysis, the regression equation for the standardized values of daily maximum ozone concentrations in the Tokyo area during August 2005 was determined to be

$$
\mathrm{O}_{3}=0.57 * T-0.68 * U, \quad R^{2}=0.7 .
$$

The $t$-tests show that the regression coefficients in (4) are statistically significant $(P$-values $<.05)$. The peak ozone concentrations predicted by the statistical regression equation for one summer month (August) were plotted against the observed values, as shown in Figure 7. An $R^{2}$ of 0.7 was obtained, which suggests that $70 \%$ of the recent shortterm variation in daily maximum ozone concentrations depends on daily maximum temperatures and daily averaged wind speeds. The peak ozone concentrations increased with increasing temperature and decreased with increasing wind speed during August 2005.

It should be noted that the effect of meteorological conditions on ozone concentrations is very complex. Temperature and wind speed can be directly and indirectly related to ozone levels. For example, a high temperature not only affects photochemical reactions but can also enhance ozone precursor emission rates and thus lead to an increase in ozone concentrations [41]. Therefore, it is necessary to consider the effect of emissions in any examination 


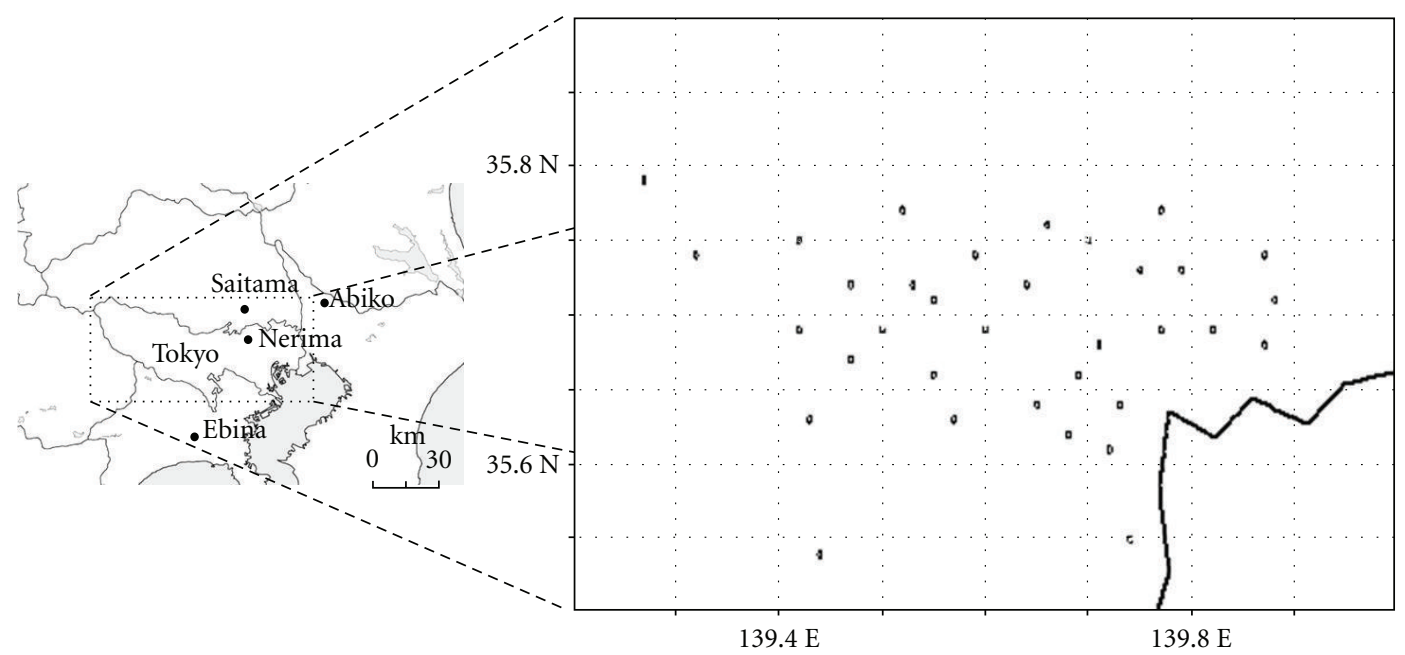

FIGURE 8: Monitoring stations used for validation of the CMAQ model and locations of the 34 environmental monitoring stations in the Tokyo area.

of the relationship between meteorological conditions and ozone concentrations. This work was done using numerical simulations and is discussed in the next section.

\subsection{Relationships between Ozone Levels and Meteorological Conditions Based on Numerical Simulations}

4.3.1. Comparison of Time Series between Simulations and Observations. To evaluate the performance of the model, the results from the CMAQ model for Domain 3 were compared to measured data from air quality monitoring sites located within the Kanto area: namely, the Nerima, Saitama, Abiko, and Ebina sites, which are shown in Figure 8. Besides the Nerima site, which has a pattern typical of urban climates in the Tokyo area, other sites that are located outside of the Tokyo were selected to confirm the overall model performance. The comparisons of the hourly averaged ozone concentrations between the CMAQ simulation and the observations from the four monitoring sites are shown in Figure 9. Generally, the model simulations had different results depending on the location of the monitoring site, and there is a good agreement between the simulated ozone concentrations, and observations. On days with low ozone concentrations, the simulations tended to overestimate the maximum and minimum ozone concentrations at all sites. Additionally, the CMAQ model also tended to underestimate the peak maximum ozone concentrations on some days when extreme ozone concentrations were observed. This may have been related to the surface boundary layer parameterization in the MM5 model [42]. In this study, a comparison of the MM5 model output with measurements has not been included. However, our other studies have previously reported such comparisons, and these support the use of this meteorological model. For example, Huang et al. [43] compared the performance of the MM5 model output for surface wind velocity and temperature with measured data and found reasonable agreement for the Kanto area of Japan.
4.3.2. Relationship between Recent Short-Term Variations in Simulated Ozone Levels and Meteorological Conditions during a Typical Summer Month. For this section, the results of the numerical simulations were used for analysis. These simulations included the daily averages for wind speeds, maximum ozone concentrations and maximum temperatures in the Tokyo area, as shown in Figure 14. All of the variables were extracted from the MM5/CMAQ simulations for Domain 3. To avoid the effect of changes in ozone precursor emissions due to changes in meteorological conditions, the emissions data were fixed at the same values for all of the simulation days. After standardizing all of the variables by (2) and applying the same procedure for the regression analysis, the regression equation for the standardized values of daily maximum ozone concentrations in August was determined to be

$$
\mathrm{O}_{3}=0.45 * T-0.66 * U, \quad R^{2}=0.66 .
$$

The results of the $t$-test show that the regression coefficients of temperature and wind speed for (5) are statistically significant $(P$-value $<.05)$. For the one summer month (August) shown in Figure 10, an $R^{2}$ of 0.66 was obtained, which suggests that $66 \%$ of the variation in daily maximum ozone concentrations may be accounted for by changes in temperature and wind speed. These results are in agreement with the measurement analytical results, though the peak ozone concentrations have a slightly weaker relationship with the changes in meteorological conditions. This difference may be due to the effect of changes in ozone precursor emissions that were associated with changes in meteorological conditions, which were not included in the CMAQ simulations.

4.3.3. The Effect of Urban Heat Islands and Local Circulation Systems. Urban heat islands have long been identified as environmental problems that affect cities all over the world, especially major cities like Tokyo, Japan. The effects of UHIs 

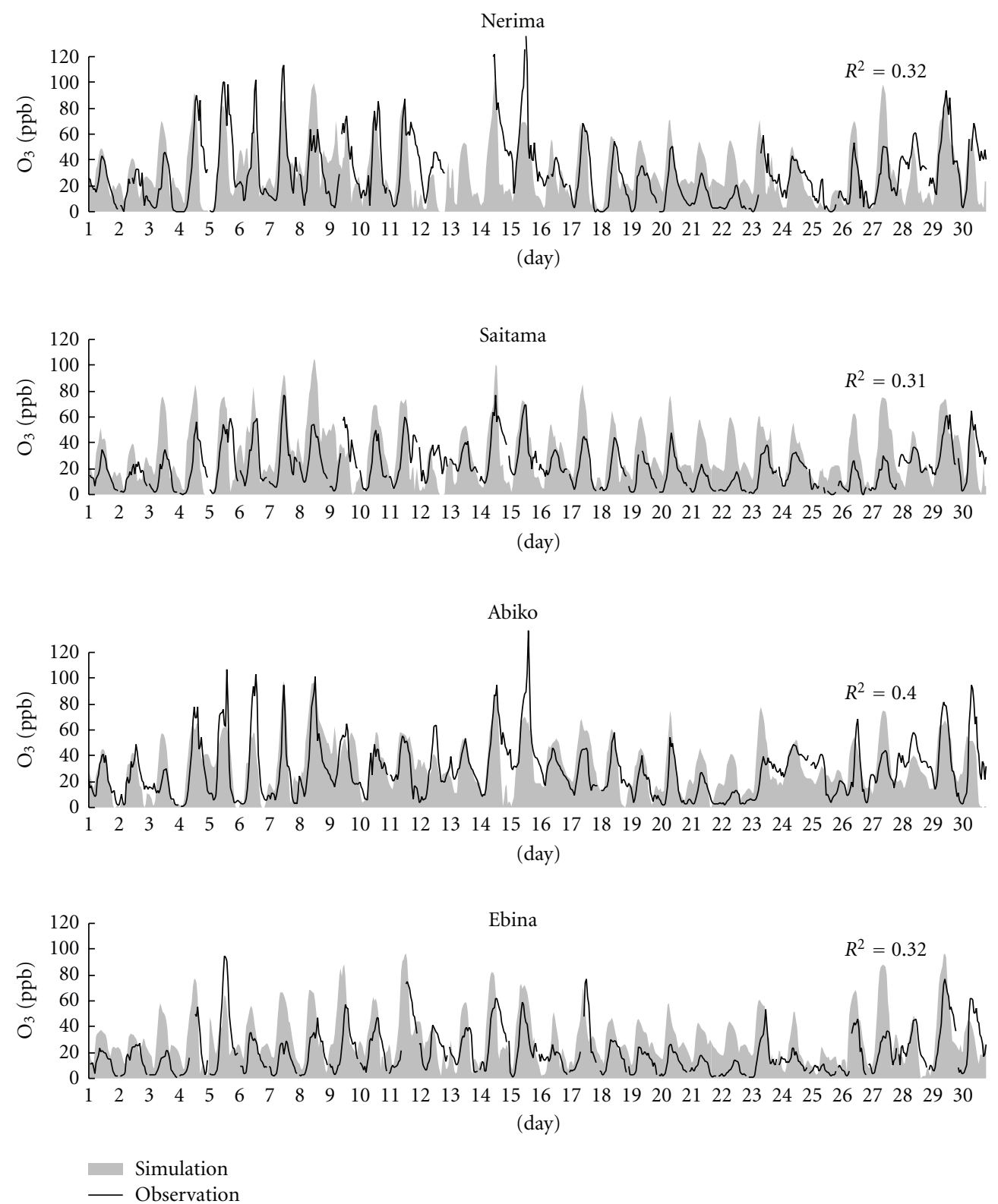

FIGURE 9: Time series for observed and simulated hourly ozone concentrations at some sites during August 2005.

on air pollution over the Kanto area have been previously reported. For example, Yoshikado [23] examined the basic characteristics of daytime heat island circulation using a twodimensional hydrostatic boundary layer model and indicated that the interaction of the circulation of Tokyo UHIs with sea breeze flows leads to unfavorable dispersion conditions for air pollutants within the city. Yoshikado and Tsuchida [24] performed observational analysis and found that the interaction between UHIs and sea breezes is an important factor causing high air pollution events during winter in this area. To further examine the relationship between UHI phenomena and air pollution levels in summer, we selected the simulation results for August 4, 2005, a day that was associated with a daytime UHI event over the Tokyo area, for analysis. On this day, the Pacific subtropical highpressure system expanded to the west (Figure 11), and its ridge covered the Kanto area; the weather was fine. The descending airflow located at the ridge of the high-pressure system played an important role in the high level of ozone formation.

Figure 12 shows the spatial distribution of the temperature at a height of two meters and the $10 \mathrm{~m}$ high winds from the MM5 simulation for Domain 3 at 12:00 JST. A region of temperature above $36^{\circ} \mathrm{C}$ was apparent over the central Kanto area, and the horizontal wind speed was a little weak. This high temperature condition is conducive to the ozone photochemistry that produces ozone pollution. Moreover, the high temperature associated with a UHI 


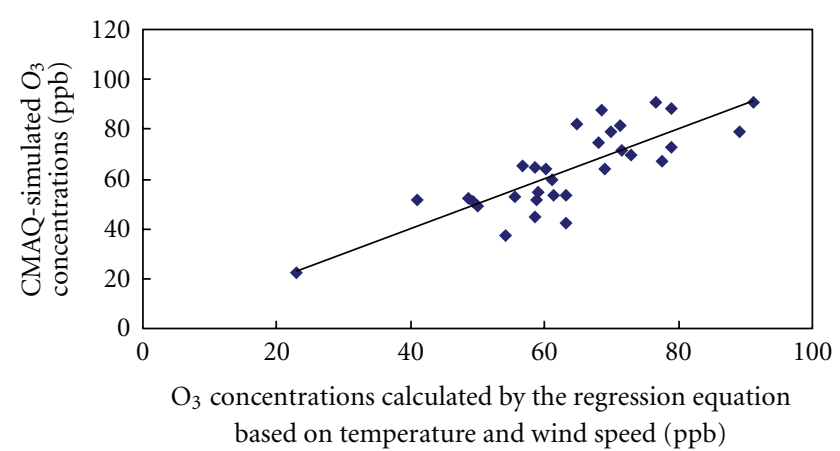

FIGURE 10: Simulated daily maximum $\mathrm{O}_{3}$ concentrations for the Tokyo area plotted against those estimated by the regression equation based on temperature and wind speed.

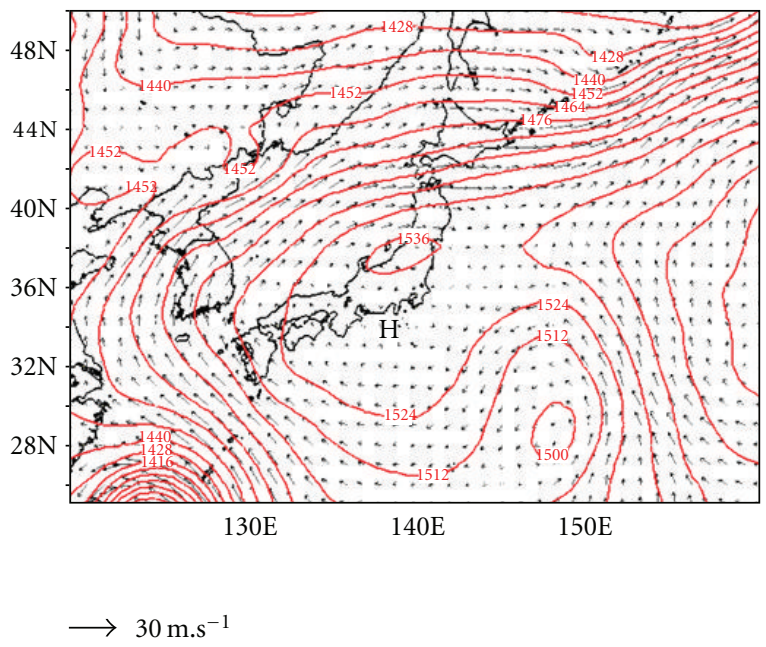

FIGURE 11: Geopotential height (gpm) and wind at $850 \mathrm{mb}$ at 9:00 JST on August 4, 2005.

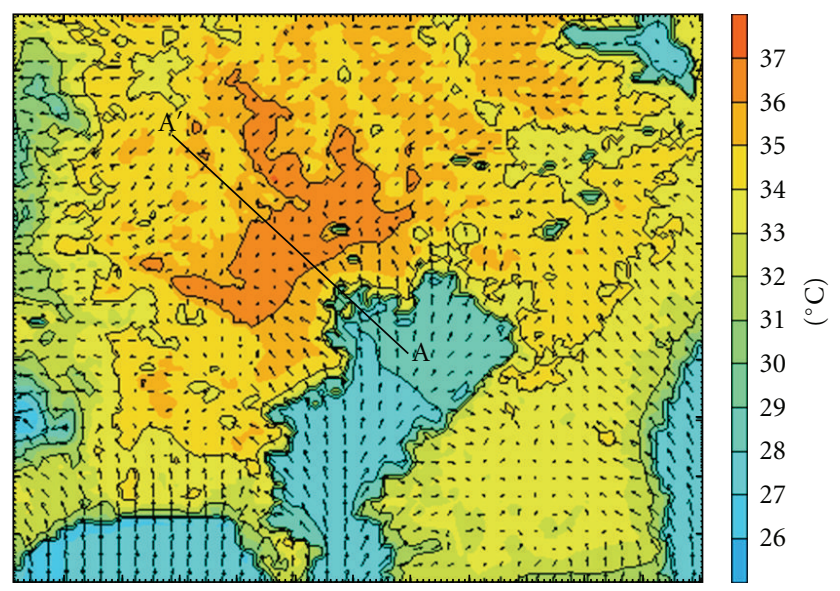

$\longrightarrow 5 \mathrm{~m} \cdot \mathrm{s}^{-1}$

Figure 12: The $2 \mathrm{~m}$ temperature $\left({ }^{\circ} \mathrm{C}\right)$ and $10 \mathrm{~m}$ wind vector simulated by the MM5 model at 12:00 JST August 4, 2005.

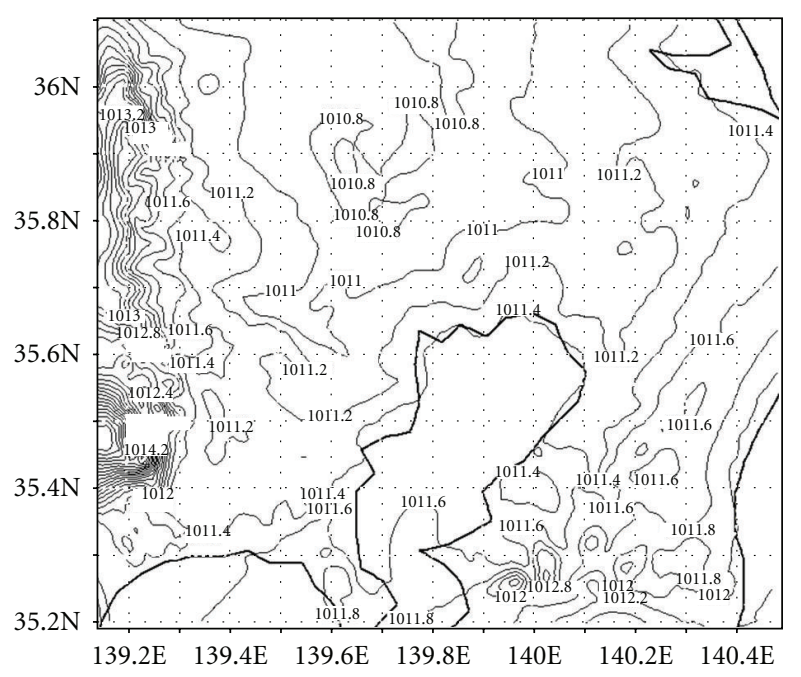

Figure 13: The sea level pressure (mb) simulated by the MM5 model at 12:00 JST August 4, 2005.

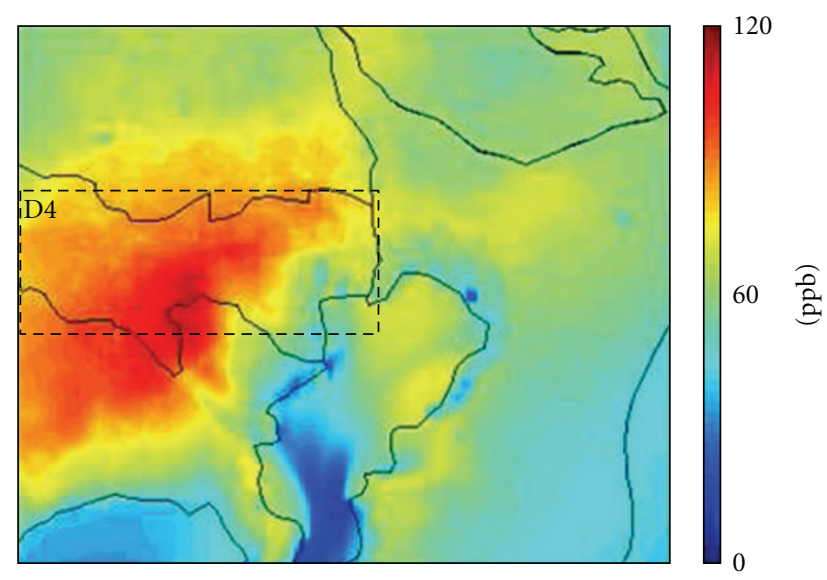

FIgURE 14: The CMAQ simulated $\mathrm{O}_{3}$ in Domain 3 at 14:00 JST on August 4, 2005; the inner box (D4) is defined as the Tokyo area that was used to extract variables for statistical analysis.

causes a pressure deficiency over the city and creates a circular pressure gradient pattern around the city as shown in Figure 13. In this situation, the sea breezes from Tokyo Bay (S-SE), Sagami Bay (SW-S) and Kashima Sea (E) merged and combined with the flow from suburban areas. This system remained stationary for several hours. Dispersion of air pollution is limited under such calm conditions, and therefore, more ozone is formed and accumulates leading to high ozone concentrations over the city, as shown in Figure 14. Although the temperature difference between the land and sea is substantial in such an instance, the sea breeze cannot pass through the city due to the persistence of UHI. This interaction between UHI and the sea breeze is also an important factor in the occurrence of high levels of ozone formation over the Kanto area and can be described by a vertical cross of the circulation vector from the shore to the suburban $A A^{\prime}$ area, as shown in Figure 15. On this day, there was no land breeze because the land surface remained hotter 


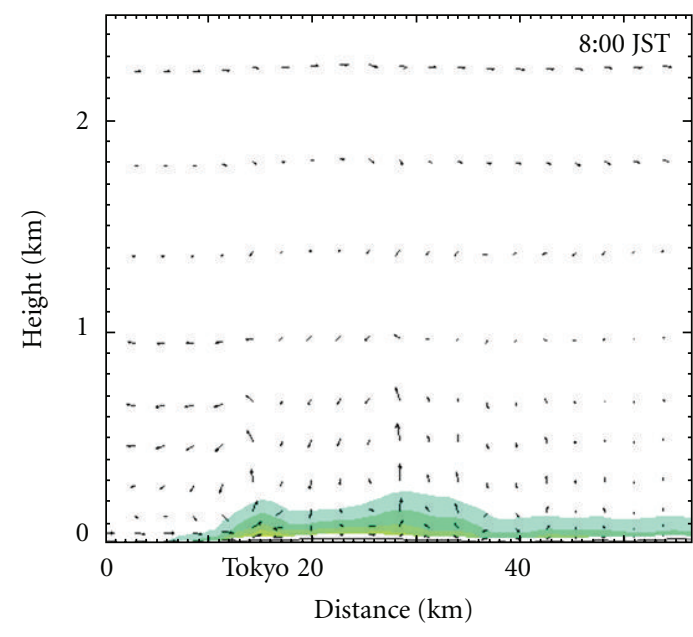

(a)

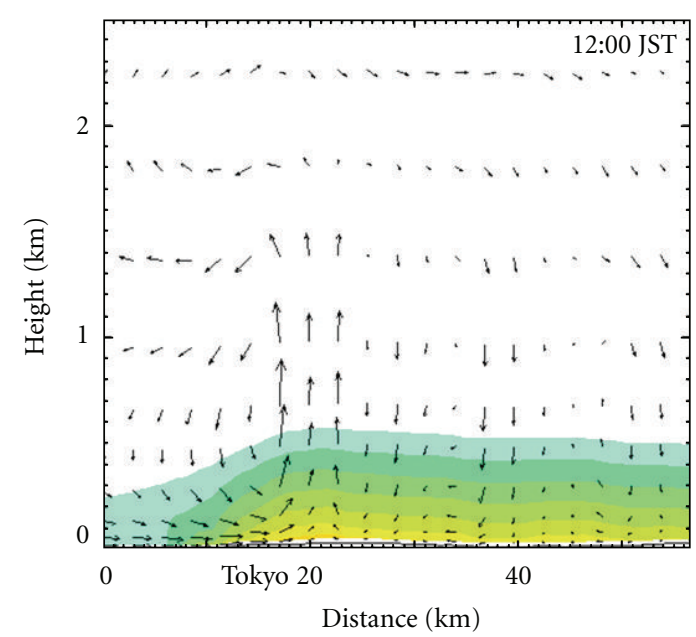

(c)

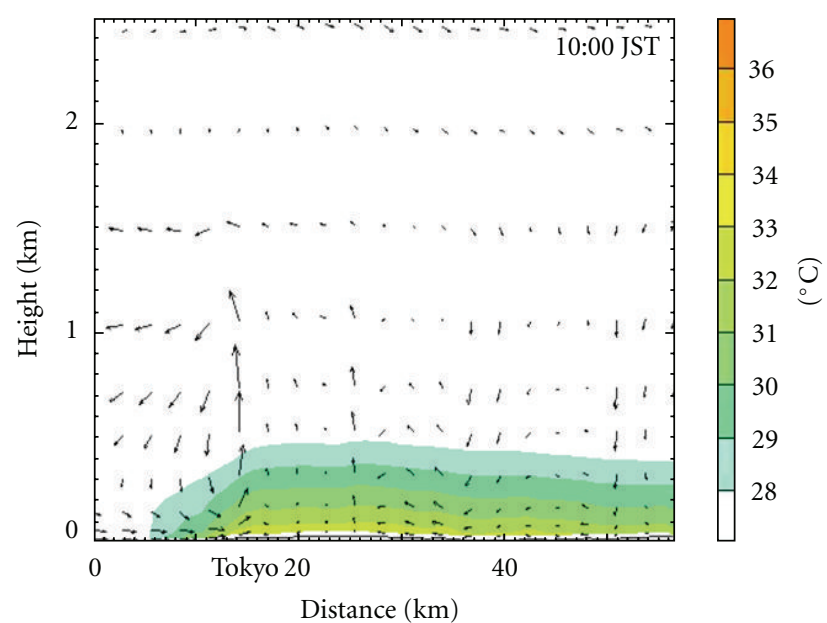

(b)
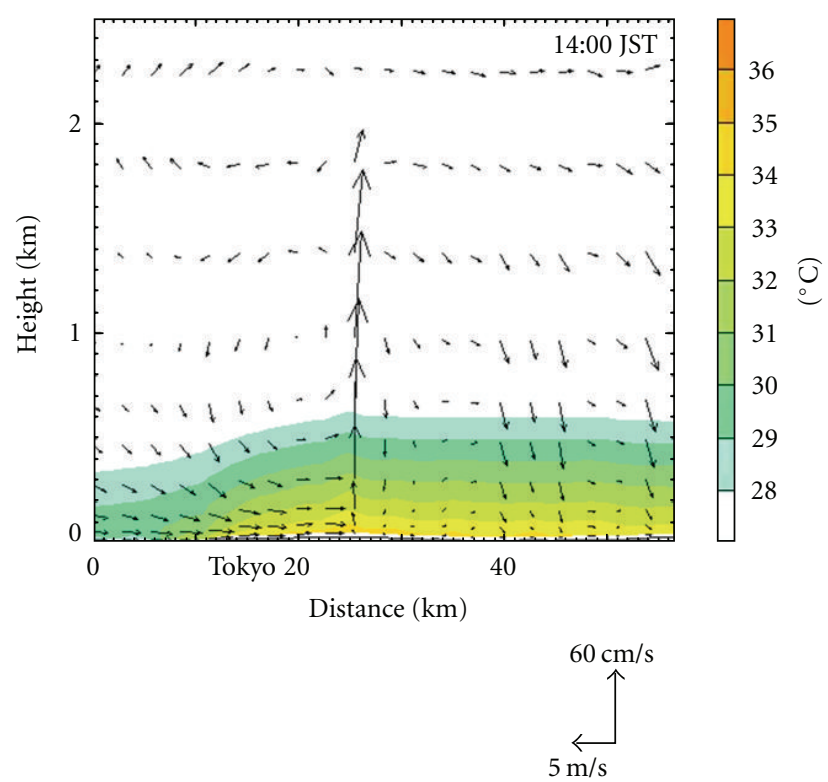

(d)

FIgURE 15: Circulation vectors and air temperatures on the plain, with cross section AA', on August 4, 2005.

than the sea surface through the previous night. During the early morning, the Tokyo Metropolitan area is calm, and a sea breeze is present near the shore and begins to penetrate inland. Until mid morning, while the surface is heated by the sun, an area of high temperature occurs across Tokyo city. The contrast in temperature between urban and suburban areas creates an urban heat island circulation (HIC). At the surface, the flow from suburban areas meets the sea breeze at the city and goes upwards. This updraft of HIC acts as a "block" that prevents the penetration of the sea breeze inland and results in more ozone accumulation over the city, which sometimes leads to extreme pollution levels.

It should be noted that a hot dry air mass under a highpressure system is believed to be one of the causes of high ozone concentrations. It is not easy to determine to what extent the high ozone levels on this day are due to the UHI phenomena or the high-pressure system; however, such high-pressure systems and their associated UHI phenomena clearly affect ozone formation. These results are consistent with a previous study that found a correlation between the trend for ground-level ozone concentrations to increase with the recent increase in frequency of high-pressure systems over the Kanto area [22].

Figure 16 shows the ozone map at 14:00 JST for August $4-7,2005$. During this period, a Pacific subtropical highpressure system extended and moved slowly westwards with the Kanto area under its ridge, which created the stagnant conditions favorable for high ozone formation (Figure 11). As seen in Figure 16, the high ozone area strongly depended on the dominance of the local circulation system during the afternoon. 


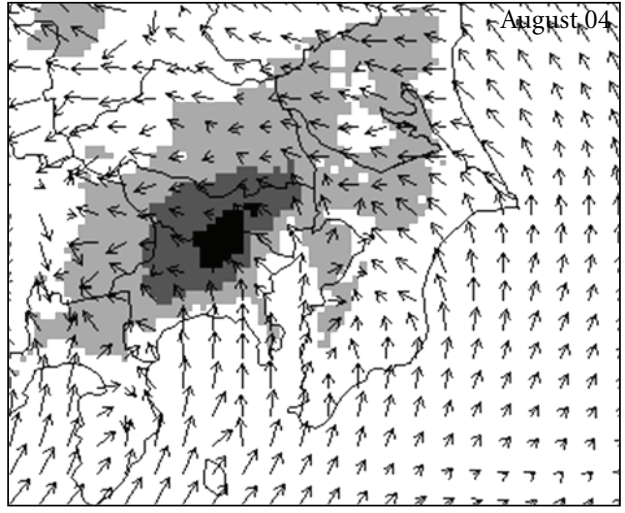

(a)

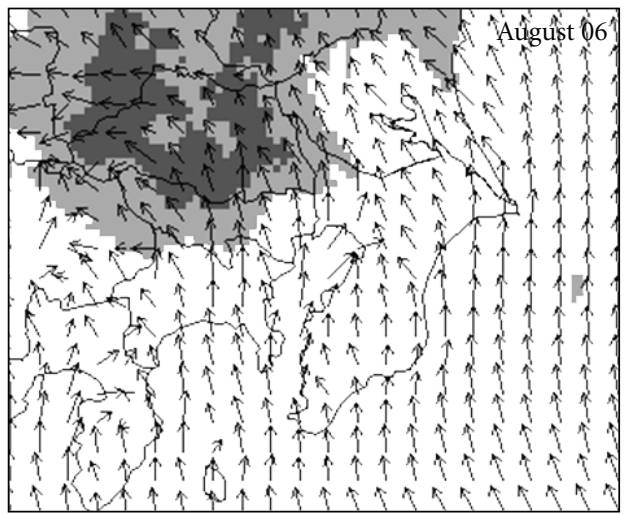

$\longrightarrow 10 \mathrm{~m} \cdot \mathrm{s}^{-1}$

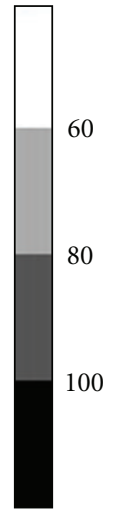

60

0

100

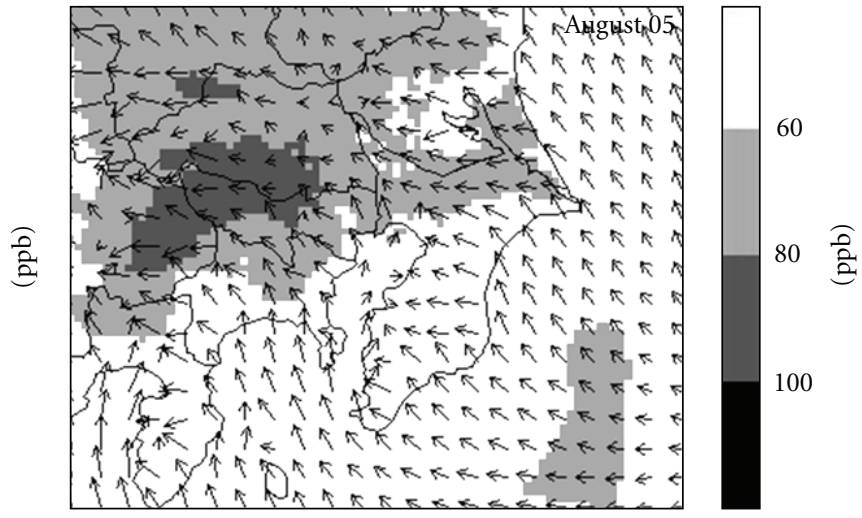

(b)

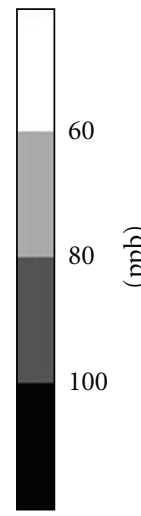

\section{है}

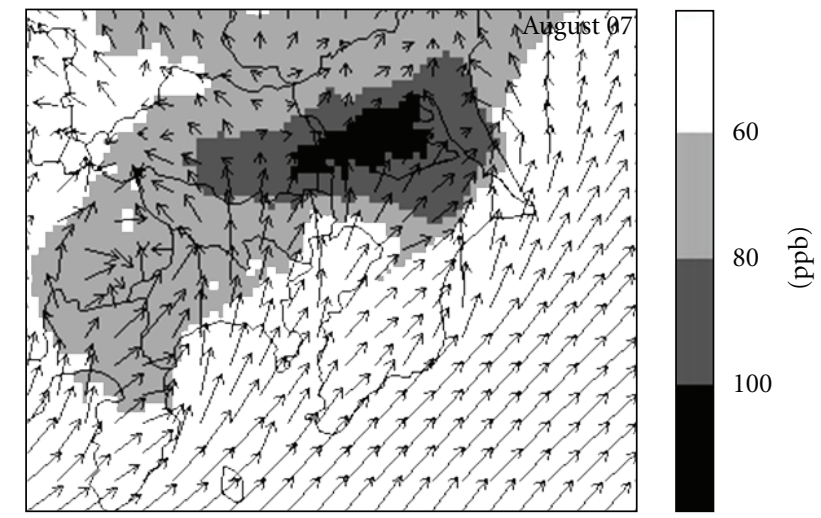

$\longrightarrow 10 \mathrm{~m} \cdot \mathrm{s}^{-1}$

(c)

(d)

FIgURE 16: The spatial distribution of ozone under various conditions of local circulation at 14:00 JST during August 4-7, 2005 over the Kanto area.

On August 4, because of the UHI effect, the sea breeze could not pass through the city. Therefore, a high ozone area was generated in the center of Tokyo and the northern part of Kanagawa. On August 5, the sea breeze was stronger, and the high ozone area moved inland and around the northwestern part of Tokyo. On August 6, a southeasterly sea breeze dominated the whole Kanto area and high ozone concentrations mainly appeared in Saitama and Gunma. On August 7, southerly and southwesterly winds dominated in the Kanto area due to the interaction between the sea breeze and powerful winds blowing in from the Pacific Ocean. Because of this wind direction, the high ozone area mainly converged in the northeastern part of Kanto. These results suggest that daily variations in the sea breeze due to interactions with other atmospheric systems have significant effects on the ozone distribution in the Kanto area.

\section{Conclusions}

Statistical regression analyses and the MM5/CMAQ numerical model were implemented to investigate the contribution of meteorological conditions to ozone concentrations in summer. The results of this study show that there is a close relationship between changes in meteorological conditions and variations in ozone concentrations over the central Kanto area. In summer, up to $84 \%$ of long-term variations in peak ozone concentrations may be accounted for by changes in the seasonally averaged daily maximum temperatures and seasonally averaged wind speeds, while about $70 \%$ of recent short-term variations in peak ozone concentrations depend on daily maximum temperatures and daily averaged wind speeds. The results suggest that changes in meteorological conditions have significant impacts upon rising ozone concentrations in this area.

These results also indicate that UHIs can play a considerable role in ozone formation in the central Kanto area. High temperatures and calm conditions under an UHI can cause high ozone levels in this area. The interaction of the UHI circulation with the sea breeze strongly affects ozone concentrations. Although the temperature difference between land and sea helps to develop a summer sea breeze, the sea breeze cannot pass through the city due to the persistence of an UHI. Therefore, dispersion of ozone is limited, and high ozone concentrations occur. The results 
also show that the penetration and dominance of a sea breeze is the main factor controlling the spatial distribution of ozone concentrations in the Kanto area.

This study suggests that the MM5/CMAQ model can be a useful tool for urban environmental analyses. However, since many processes and mechanisms affect ozone concentrations, it is necessary to develop a model that fully describes all of the chemical and physical processes involved in causing high pollution levels, including the complex interactions between topography, city building environments, land use, and anthropogenic emissions.

\section{References}

[1] M. Lippmann, "Health effects of tropospheric ozone," Environmental Science and Technology, vol. 25, no. 12, pp. 19541962, 1991.

[2] T. Ohara, I. Uno, S. Wakamatsu, and K. Murano, "Numerical simulation of the springtime transboundary air pollution in East Asia," Water, Air, and Soil Pollution, vol. 130, no. 1-4, pp. 295-300, 2001.

[3] T. Ohara, K. Yamaji, I. Uno, et al., "Long-term simulations of surface ozone in East Asia during 1980-2020 with CMAQ and REAS," in Environmental Security, Air Pollution Modeling and Its Application XIX, C. Borrego and A. I. Miranda, Eds., NATO Science for Peace 20 and Security Series C, 2008.

[4] H. Akimoto, "Global air quality and pollution," Science, vol. 302, no. 5651, pp. 1716-1719, 2003.

[5] K. Yamaji, T. Ohara, I. Uno, H. Tanimoto, J.-I. Kurokawa, and H. Akimoto, "Analysis of the seasonal variation of ozone in the boundary layer in East Asia using the community multiscale air quality model: what controls surface ozone levels over Japan?" Atmospheric Environment, vol. 40, no. 10, pp. 1856$1868,2006$.

[6] A. Kannari and T. Ohara, "A long term trend of VOC's photochemical reactivity in Japan," in IGAC 10th International Conference, Annecy, France, 2008.

[7] I. Uno, S. Wakamatsu, M. Suzuki, and Y. Ogawa, "Threedimensional behaviour of photochemical pollutants covering the Tokyo metropolitan area," Atmospheric Environment, Part A, vol. 18, no. 4, pp. 751-761, 1984.

[8] T. D. Davies, P. M. Kelly, P. S. Low, and C. E. Pierce, "Surface ozone concentrations in Europe: links with the regional-scale atmospheric circulation," Journal of Geophysical Research, vol. 97, no. 9, pp. 9819-9832, 1992.

[9] A. C. Comrie and B. Yarnal, "Relationships between synopticscale atmospheric circulation and ozone concentrations in metropolitan Pittsburgh, Pennsylvania," Atmospheric Environment, Part B, vol. 26, no. 3, pp. 301-312, 1992.

[10] J. Zhang, S. T. Rao, and S. M. Daggupaty, "Meteorological processes and ozone exceedances in the northeastern United States during the 12-16 July 1995 episode," Journal of Applied Meteorology, vol. 37, no. 8, pp. 776-789, 1998.

[11] P. Solomon, E. Cowling, G. Hidy, and C. Furiness, "Comparison of scientific findings from major ozone field studies in North America and Europe," Atmospheric Environment, vol. 34, no. 12-14, pp. 1885-1920, 2000.

[12] C. Dueñas, M. C. Fernández, S. Caete, J. Carretero, and E. Liger, "Assessment of ozone variations and meteorological effects in an urban area in the Mediterranean Coast," Science of the Total Environment, vol. 299, no. 1-3, pp. 97-113, 2002.
[13] H. K. Elminir, "Dependence of urban air pollutants on meteorology," Science of the Total Environment, vol. 350, no. 1-3, pp. 225-237, 2005.

[14] W. M. Cox and S.-H. Chu, "Assessment of interannual ozone variation in urban areas from a climatological perspective," Atmospheric Environment, vol. 30, no. 14, pp. 2615-2625, 1996.

[15] P. Bloomfield, J. A. Royle, L. J. Steinberg, and Q. Yang, "Accounting for meteorological effects in measuring urban ozone levels and trends," Atmospheric Environment, vol. 30, no. 17, pp. 3067-3077, 1996.

[16] K. J. Olszyna, M. Luria, and J. F. Meagher, "The correlation of temperature and rural ozone levels in southeastern U.S.A," Atmospheric Environment, vol. 31, no. 18, pp. 3011-3022, 1997.

[17] L. M. Cárdenas, J. F. Austin, R. A. Burgess et al., "Correlations between $\mathrm{CO}, \mathrm{NO}_{\mathrm{y}}, \mathrm{O}_{3}$ and non-methane hydrocarbons and their relationships with meteorology during winter 1993 on the North Norfolk Coast, U.K," Atmospheric Environment, vol. 32, no. 19, pp. 3339-3351, 1998.

[18] O. A. Tarasova and A. Y. Karpetchko, "Accounting for local meteorological effects in the ozone time-series of Lovozero (Kola Peninsula)," Atmospheric Chemistry and Physics, vol. 3, pp. 941-949, 2003.

[19] J. Tu, Z.-G. Xia, H. Wang, and W. Li, “Temporal variations in surface ozone and its precursors and meteorological effects at an urban site in China," Atmospheric Research, vol. 85, no. 3-4, pp. 310-337, 2007.

[20] K.-J. Cheng, C.-H. Tsai, H.-C. Chiang, and C.-W. Hsu, "Meteorologically adjusted ground level ozone trends in southern Taiwan," Environmental Monitoring and Assessment, vol. 129, no. 1-3, pp. 339-347, 2007.

[21] E. Kovač-Andrić, J. Brana, and V. Gvozdić, "Impact of meteorological factors on ozone concentrations modelled by time series analysis and multivariate statistical methods," Ecological Informatics, vol. 4, no. 2, pp. 117-122, 2009.

[22] H. Yoshikado and T. Tsubaki, "Upward trends in photochemical oxidants and climate change in summer in the greater Tokyo region," in Proceedings of the 13th World Clean Air and Environmental Protection Congress, pp. 1-6, London, UK, 2004, CD-ROM.

[23] H. Yoshikado, "Numerical study of the daytime urban effect and its interaction with the sea breeze," Journal of Applied Meteorology, vol. 31, no. 10, pp. 1146-1164, 1992.

[24] H. Yoshikado and M. Tsuchida, "High levels of winter air pollution under the influence of the urban heat island along the shore of Tokyo Bay," Journal of Applied Meteorology, vol. 35, no. 10, pp. 1804-1813, 1996.

[25] H. Yoshikado, "Air pollution in Japan dominated by local meteorology," Journal of Japan Society for Atmospheric Environment, vol. 42, no. 2, pp. 63-74, 2004 (Japanese).

[26] S. Wakamatsu, Y. Ogawa, K. Murano, K. Goi, and Y. Aburamoto, "Aircraft survey of the secondary photochemical pollutants covering the Tokyo metropolitan area," Atmospheric Environment, vol. 17, no. 4, pp. 827-835, 1983.

[27] S. Wakamatsu, I. Uno, and M. Suzuki, "A field study of photochemical smog formation under stagnant meteorological conditions," Atmospheric Environment, Part A, vol. 24, no. 5, pp. 1037-1050, 1990.

[28] H. Kurita, K. Sasaki, H. Muroga, H. Ueda, and S. Wakamatsu, "Long-range transport of air pollution under light gradient wind conditions," Journal of Climate and Applied Meteorology, vol. 24, pp. 425-434, 1985. 
[29] H. Kurita and H. Ueda, "Meteorological conditions for longrange transport under light gradient winds," Atmospheric Environment, Part A, vol. 20, no. 4, pp. 687-694, 1986.

[30] F. Fujibe, "Air pollution in the surface layer accompanying a local front at the onset of the land breeze," Journal of the Meteorological Society of Japan, vol. 53, pp. 226-237, 1985.

[31] F. Fujibe, "Long-term changes in wind speed observed at AMeDAS stations," Tenki, vol. 50, pp. 457-460, 2003 (Japanese).

[32] F. Fujibe, "Detection of urban warming in recent temperature trends in Japan," International Journal of Climatology, vol. 29, no. 12, pp. 1811-1822, 2009.

[33] J. Dudhia, D. Gill, R. G. Yong, and K. Manning, "PSU/NCAR Mesoscale Modeling System. Tutorial Class Notes and User's Guide,” MM5 Modeling System Version 3, 2005.

[34] D. Byun and J. Ching, "Science algorithms of the EPA Models3 Community Multiscale Air Quality (CMAQ) modeling system," US Environmental Protection Agency, EPA-600/R99/030, 1999.

[35] G. A. Grell, J. Dudhia, and D. R. Stauffer, "A description of the fifth-generation Penn State/NCAR mesoscale model (MM5)," NCAR Technical Note NCAR/TN-398+STR, 1994.

[36] S.-Y. Hong and H.-L. Pan, "Nonlocal boundary layer vertical diffusion in a medium-range forecast model," Monthly Weather Review, vol. 124, no. 10, pp. 2322-2339, 1996.

[37] E.-Y. Hsie and R. A. Anthes, "Simulations of frontogenesis in a moist atmosphere using alternative parameterizations of condensation and precipitation," Journal of the Atmospheric Sciences, vol. 41, no. 18, pp. 2701-2716, 1984.

[38] J. Dudhia, "Numerical study of convection observed during the winter monsoon experiment using a mesoscale twodimensional model," Journal of the Atmospheric Sciences, vol. 46, no. 20, pp. 3077-3107, 1989.

[39] H. Hayami and S. Kobayashi, "Modeling of concentration of atmospheric secondary aerosol," CRIEPI Report T03037, 2004.

[40] JCAP, Air Modeling (4), “Observation results of Kanto area in summer,” Tech. Rep., Japan Clean Air Program, 1999.

[41] D. Narumi, A. Kondo, and Y. Shimoda, "The effect of the increase in urban temperature on the concentration of photochemical oxidants," Atmospheric Environment, vol. 43, no. 14, pp. 2348-2359, 2009.

[42] R. Vautard, M. Beekmann, B. Bessagnet, et al., "The use of MM5 for operational ozone/NOx/aerosols prediction in Europe: strengths and weaknesses of MM5," in MM5 Workshop, pp. 1-4, Boulder, Colo, USA, June 2004.

[43] H. Huang, R. Ooka, M. V. Khiem, and H. Hayami, "Numerical simulation of air pollution over Kanto area in Japan using the MM5/CMAQ model—comparison of air pollution concentration between two different climatic days," in Proceedings of the 7th Symposium on the Urban Environment, American Meteorological Society (AMS '07), pp. 1-8, San Diego, Calif, USA, 2007. 

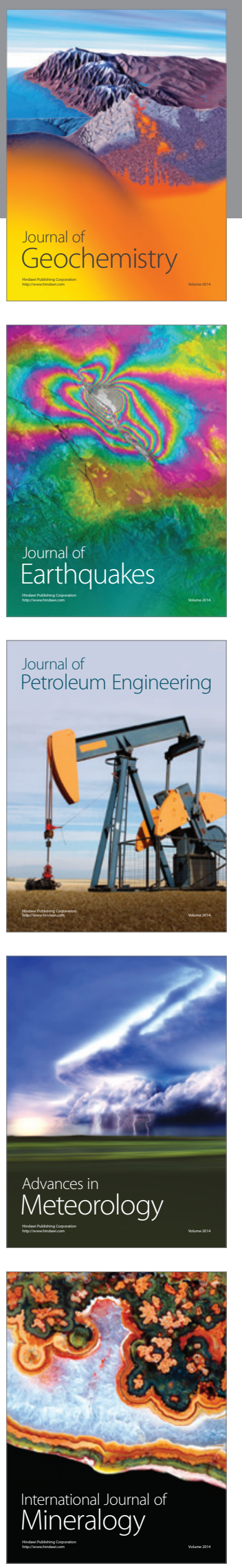
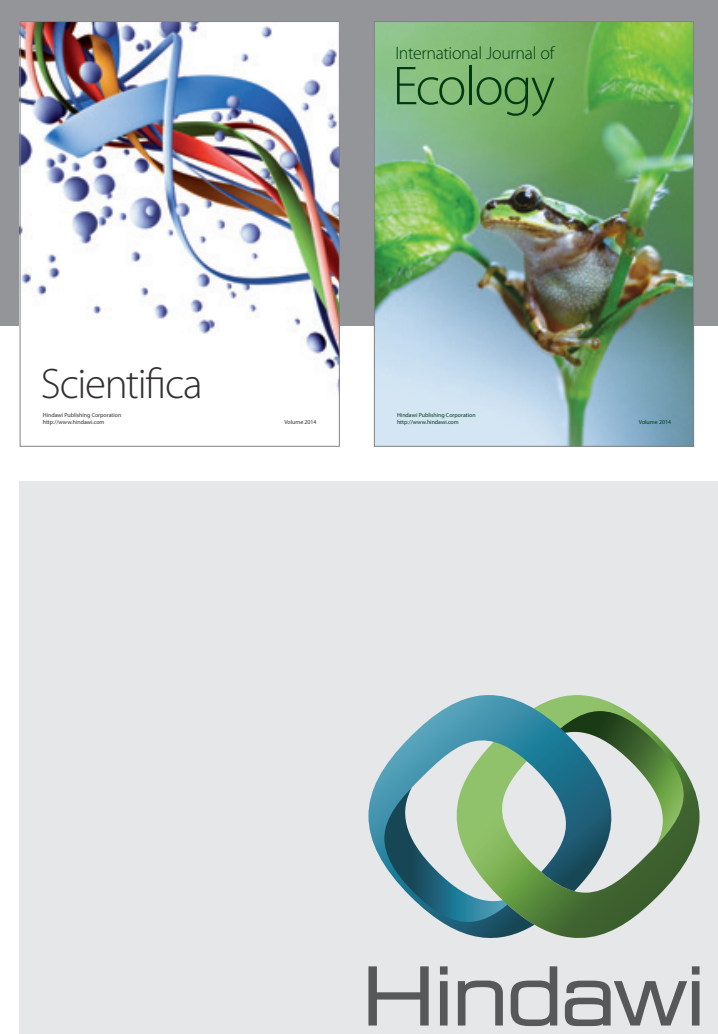

Submit your manuscripts at http://www.hindawi.com
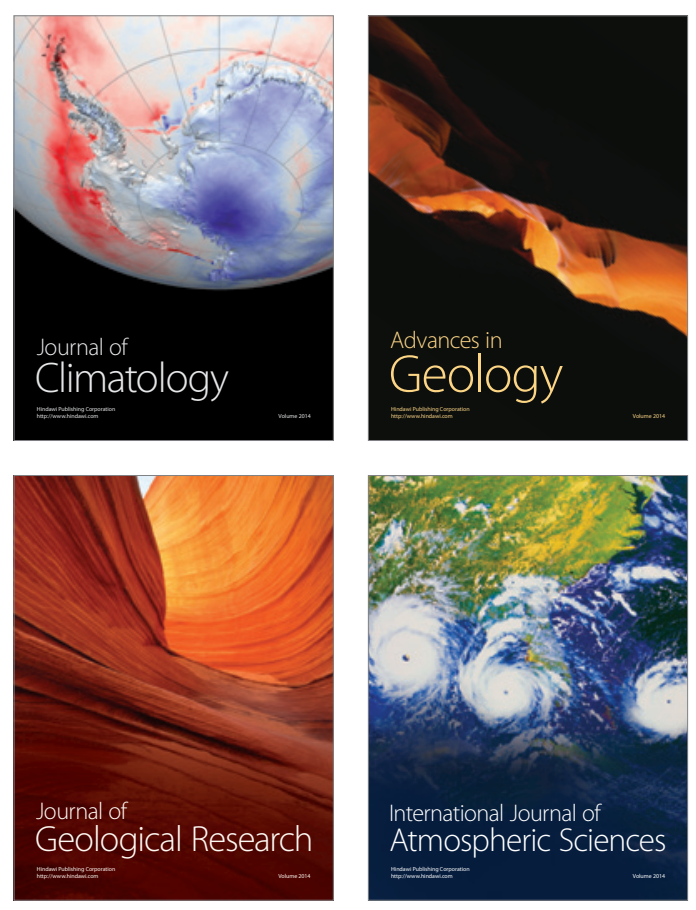
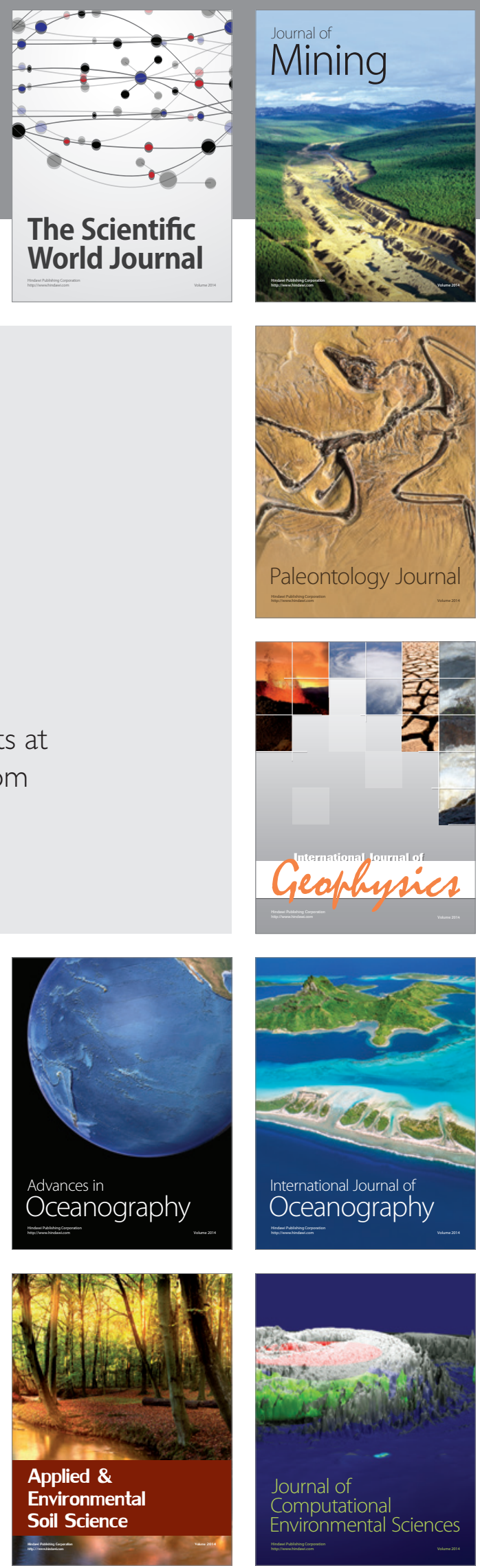